\title{
Enhanced recovery after elective colorectal surgery: now the standard of care
}

\author{
E. J. Andrews • M. McCourt • M. G. O'Ríordáin
}

Received: 26 November 2007/ Accepted: 24 March 2011/Published online: 13 April 2011

(C) Royal Academy of Medicine in Ireland 2011

\begin{abstract}
Enhanced recovery programmes have been studied in randomised trials with evidence of quicker recovery of gut function, reduced morbidity, mortality and hospital stay and improved physiological and nutritional outcomes. They aim to reduce the physiological and psychological stress of surgery and consequently the uncontrolled stress response. The key elements, reduced pre-operative fasting, intravenous fluid restriction and early feeding after surgery, are in conflict with traditional management plans but are supported by strong clinical evidence. Given the strength of the current data enhanced recovery should now be the standard of care.
\end{abstract}

Keywords Colorectal surgery - Enhanced recovery · Post-operative complications - Laparoscopic surgery · Colorectal cancer $\cdot$ Fast track surgery

\section{Introduction}

Enhanced recovery programmes for patients undergoing elective colorectal surgery aim to optimise pre-operative, peri-operative and post-operative factors to reduce the physiological and psychological stress of surgery [1]. They are also known as fast track surgery, multi-modal intervention or optimisation or accelerated rehabilitation. The philosophy is that traditional care exposes patient to

E. J. Andrews $(\bowtie) \cdot$ M. McCourt · M. G. O’Ríordáin Department of Colorectal Surgery,

Cork University Hospital, Cork, Ireland

e-mail: emmetandrews@eircom.net

E. J. Andrews · M. McCourt · M. G. O’Ríordáin

Department of Colorectal Surgery,

Mercy University Hospital, Cork, Ireland unnecessary fasting, excess intravenous fluids and consequently an uncontrolled stress response.

The key elements are to eliminate factors that inhibit the patient returning home after surgery, especially pain control, establishing oral intake and ensuring adequate mobility to allow activities of daily life. These elements are divided into pre-operative, intra-operative and post-operative factors [1].

\section{Pre-operative factors}

The pre-operative factors that are important in enhanced recovery programmes are conditioning of patient expectations, assessing co-morbid risk assessment, bowel preparation and optimising peri-operative nutrition.

Counselling with the patient and their primary carer in the outpatient setting prior to admission is essential [2]. The aim is to outline the process the patient will undergo while an inpatient, what is expected of them during this time, and the estimated day of discharge to allow adequate preparation of the carer for the patient in the discharge environment [2]. This should be reinforced with the provision of written information.

Co-morbid disease and risk profile need to be optimised prior to admission with functional assessment of respiratory and cardiac performance to identify patients who are at greater risk of complications [3]. Oral nutritional supplementation should be started before hospital admission as it significantly diminishes the degree of weight loss and incidence of minor complications [4].

In most enhanced recovery programmes no mechanical bowel preparation is given. Mechanical bowel preparation does not decrease anastomotic leak rates and increases the risk of abdominal infectious complications [5]. 
There is no scientific support for fasting after midnight before elective surgery and there is evidence that it is harmful [6]. An $800 \mathrm{ml}$ carbohydrate-rich beverage before midnight and $400 \mathrm{ml} 2 \mathrm{~h}$ before surgery may be safely given to reduce pre-operative thirst, hunger and anxiety and also to reduce post-operative insulin resistance [7].

\section{Intra-operative factors}

Anaesthesia involves thoracic epidural with bupivicaine (T8-T9), limited and standardised intra-operative fluid and local anaesthesia infiltration to the largest wound. The requirements are early awakening after finishing surgery, minimal use of opiates, epidural analgesia with combinations of marcaine, bupivicaine and fentanil and avoidance of fluid overload [3]. Intra- and post-operative fluid overload is associated with significantly increased morbidity.

No nasogastric tubes or surgical drains are left in the patient as they slow the return of bowel function and increase pulmonary complications without reducing anastomotic rates $[8,9]$.

\section{Post-operative factors}

The four main post-operative factors in enhanced recovery programmes are pain relief, fluid balance, mobilisation and discharge planning.

Optimal pain relief is provided by continuous epidural analgesia for $48 \mathrm{~h}$ in addition to regular paracetamol and non-steroidal anti-inflammatory drug or equivalent [3].

Patients should not be kept nil by mouth after surgery. Early enteral feeding on the first post-operative day reduces the risk of any type of infection and the length of hospital stay [10].

A positive salt and water balance after surgery delays return of gastrointestinal function and prolongs hospital stay in patients undergoing elective colonic resection [11]. A restricted peri-operative intravenous fluid regimen reduces respiratory, abdominal and wound complications after elective colorectal resection [12].

Early mobilisation with aggressive post-operative physiotherapy is essential. The urinary catheter is removed on the first post-operative day for colonic resections and on day three for rectal resections.

\section{Evidence}

Enhanced recovery programmes have been studied since 1990s with evidence of quicker recovery of gut function, reduced morbidity and hospital stay [13] and evidence of improved physiological and nutritional outcomes [14]. Several randomized trials have confirmed these findings and are summarised in a systematic review incorporating 512 patients [15]. Primary hospital stay and morbidity were significantly lower for patients on enhanced recovery programmes. Readmission rates were not significantly different and there was no increase in mortality. Enhanced recovery programmes appear to be safe and shorten hospital stay after elective colorectal surgery. These programmes reduce overall complication rates, especially cardiopulmonary complications [15].

Randomised comparisons between elective laparoscopic or open colonic resection with enhanced recovery programmes have shown similar recovery to normal activities and gastrointestinal function [16]. There were no significant differences in postoperative morbidity, mortality, or readmissions, demonstrating that functional recovery after colonic resection is rapid with an enhanced recovery programme and without differences between open and laparoscopic. A further randomized clinical trial comparing laparoscopic and open surgery for colorectal cancer within an enhanced recovery programme showed that length of hospital stay after laparoscopic resection was shorter than for open resection [17]. Despite peri-operative optimisation of open surgery for colorectal cancer, short-term outcomes were better following laparoscopic surgery [18].

Enhanced recovery is a multi-disciplinary approach that must include anaesthetists, counsellors, stoma therapist, physiotherapists, nursing staff, dieticians and surgeons. Organisational support and resources are important but not essential for its establishment. Surgeons must drive the introduction of these programmes and given the strength of the current data enhanced recovery programmes for patients undergoing elective colorectal surgery should now be the standard of care.

\section{References}

1. Wilmore DW, Kehlet H (2001) Management of patients in fast track surgery. BMJ 322:473-476

2. Fearon KCH, Ljungqvist O, Von Meyenfeldt $\mathrm{M}$ et al (2005) Enhanced recovery after surgery: a consensus review of clinical care for patients undergoing colonic resection. Clin Nutr 24(3): 466-477

3. Kehlet H, Dahl J (2003) Anaesthesia, surgery, and challenges in postoperative recovery. Lancet 362(9399):1921-1928

4. Smedley F, Bowling T, James M et al (2004) A randomized clinical trial of the effects of preoperative and postoperative oral nutritional supplements on clinical course and cost of care. Br J Surg 91(8):983-990

5. Guenaga K, Atallah AN, Castro AA, Matos DDM, WilleJørgensen P (2003) Mechanical bowel preparation for elective colorectal surgery. Cochrane Database Syst Rev (2):CD001544 
6. Brady M, Kinn S, Stuart P (2003) Preoperative fasting for adults to prevent perioperative complications. Cochrane Database Syst Rev (4):CD004423

7. Noblett SE, Watson DS, Huong H, Davison B, Hainsworth PJ, Horgan AF (2006) Pre-operative oral carbohydrate loading in colorectal surgery: a randomized controlled trial. Colorectal Dis 8:563-569

8. Nelson R, Edwards S, Tse B (2007) Prophylactic nasogastric decompression after abdominal surgery. Cochrane Database Syst Rev (3):CD004929

9. French Association for Surgical Research (1999) Is prophylactic pelvic drainage useful after elective rectal or anal anastomosis? A multicenter controlled randomised trial. Surgery 125: 529-35

10. Andersen HK, Lewis SJ, Thomas S (2006) Early enteral nutrition within $24 \mathrm{~h}$ of colorectal surgery versus later commencement of feeding for postoperative complications. Cochrane Database Syst Rev (4):CD004080

11. Lobo DN, Bostock KA, Neal KR et al (2002) Effect of salt and water balance on recovery of gastrointestinal function after elective colonic resection: a randomised controlled trial. Lancet 359(9320):1812-1818

12. Brandstrup B, Danish Study Group on Perioperative Fluid Therapy et al (2003) Effects of intravenous fluid restriction on postoperative complications: comparison of two perioperative fluid regimens: a randomized assessor-blinded multicenter trial. Ann Surg 238(5):641-648

13. Moiniche S, Bulow S, Hesselfeldt P, Hestbaek A, Kehlet H (1995) Convalescence and hospital stay after colonic surgery with balanced analgesia, early oral feeding, and enforced mobilisation. Eur J Surg 161(4):283-288

14. Basse L, Raskov HH, Hjort Jakobsen D et al (2002) Accelerated postoperative recovery programme after colonic resection improves physical performance, pulmonary function and body composition. Br J Surg 89(4):446-453

15. Walter CJ, Collin J, Dumville JC, Drew PJ, Monson JR (2009) Enhanced recovery in colorectal resections: a systematic review and meta-analysis. Colorectal Dis 11(4):344-353

16. Basse L, Jakobsen DH, Bardram L et al (2005) Functional recovery after open versus laparoscopic colonic resection: a randomized, blinded study. Ann Surg 241(3):416-423

17. King PM, Blazeby JM, Ewings P et al (2006) Randomized clinical trial comparing laparoscopic and open surgery for colorectal cancer within an enhanced recovery programme. Br J Surg 93(3):300-308

18. King PM, Blazeby JM, Ewings P et al (2006) The influence of an enhanced recovery programme on clinical outcomes, costs and quality of life after surgery for colorectal cancer. Colorectal Dis $8(6): 506-513$ 